\title{
Activation of Metabotropic Glutamate Receptor 5 in the Amygdala Modulates Pain-Like Behavior
}

\author{
Benedict J. Kolber, ${ }^{1}$ Michael C. Montana, ${ }^{1,2}$ Yarimar Carrasquillo, ${ }^{1}$ Jian Xu, ${ }^{3}$ Stephen F. Heinemann, ${ }^{3}$ Louis J. Muglia, ${ }^{4}$ \\ and Robert W. Gereau IV ${ }^{1,2}$ \\ ${ }^{1}$ Washington University Pain Center, Department of Anesthesiology and ${ }^{2}$ Program in Neuroscience, Washington University, St. Louis, Missouri 63110, ${ }^{3}$ The \\ Salk Institute for Biological Studies, Molecular Neurobiology Laboratory, La Jolla, California 92037, and ${ }^{4}$ Department of Pediatrics and Molecular \\ Physiology and Biophysics, Vanderbilt University, Nashville, Tennessee 37232
}

The central nucleus of the amygdala $(\mathrm{CeA})$ has been identified as a site of nociceptive processing important for sensitization induced by peripheral injury. However, the cellular signaling components underlying this function remain unknown. Here, we identify metabotropic glutamate receptor 5 (mGluR5) as an integral component of nociceptive processing in the CeA. Pharmacological activation of mGluRs with $(R, S)$-3,5-dihydroxyphenylglycine (DHPG) in the CeA of mice is sufficient to induce peripheral hypersensitivity in the absence of injury. DHPG-induced peripheral hypersensitivity is reduced via pharmacological blockade of mGluR5 or genetic disruption of mGluR5. Furthermore, pharmacological blockade or conditional deletion of mGluR5 in the CeA abrogates inflammation-induced hypersensitivity, demonstrating the necessity of mGluR5 in CeA-mediated pain modulation. Moreover, we demonstrate that phosphorylation of extracellular-signal regulated kinase 1/2 (ERK1/2) is downstream of mGluR5 activation in the CeA and is necessary for the full expression of peripheral inflammation-induced behavioral sensitization. Finally, we present evidence of right hemispheric lateralization of mGluR5 modulation of amygdalar nociceptive processing. We demonstrate that unilateral pharmacological activation of mGluR5 in the CeA produces distinct behavioral responses depending on whether the right or left amygdala is injected. We also demonstrate significantly higher levels of mGluR5 expression in the right amygdala compared with the left under baseline conditions, suggesting a potential mechanism for right hemispheric lateralization of amygdala function in pain processing. Together, these results establish an integral role for mGluR5 and ERK1/2 in nociceptive processing in the CeA.

\section{Introduction}

The amygdala is selectively activated in both humans and rodents during pain (Schneider et al., 2001; Lu et al., 2004; Han and Neugebauer, 2005; Carrasquillo and Gereau, 2007; Ikeda et al., 2007). Within the amygdala, the central nucleus (CeA) is well positioned to regulate nociceptive processing via input through the spino-parabrachio-amygdaloid pathway or through the basolateral nucleus of the amygdala (BLA) (Neugebauer et al., 2004). Within the CeA, the laterocapsular division (CeLC) has been identified as a putative pain regulatory center, in part because of the sensitivity of neurons within this region to noxious stimuli.

After induction of painful arthritis in rats, neurons in the CeLC exhibit increased baseline firing and an enhanced response to noxious stimuli (Li and Neugebauer, 2004). In addition, acti-

Received March 9, 2010; revised April 28, 2010; accepted May 7, 2010.

This work was supported by National Institutes of Health (NIH) Grants F31MH075250 (B.J.K.), F32NS067761 (B.J.K.), F30NS064626 (M.C.M.), F31NS046884 (Y.C.), R01DA018247 (S.F.H.), P01AG010435 (S.F.H.), R01MH079010 (L.J.M.), and R21NS061294 (R.W.G.), the Alafi Neuroimaging Laboratory, the Hope Center for Neurological Disorders, and NIH Neuroscience Blueprint Center Core Grant P30NS057105 to Washington University. We thank Benedict Alter and Maria Elena Morales for manuscript editing.

Correspondence should be addressed to Dr. Robert Gereau IV, Washington University Pain Center, Department of Anesthesiology, Washington University in St. Louis, 660 South Euclid Avenue, Box 8054, St. Louis, M0 63110. E-mail: gereaur@wusm.wustl.edu.

DOI:10.1523/JNEUROSCI.1216-10.2010

Copyright $\odot 2010$ the authors $\quad 0270-6474 / 10 / 308203-11 \$ 15.00 / 0$ vation of CeLC group I metabotropic glutamate receptors (mGluR1 and mGluR5) with the selective group I mGluR agonist $(R, S)$-3,5-dihydroxyphenylglycine (DHPG) potentiates the response of CeLC neurons to painful stimuli (Neugebauer et al., 2003; Li and Neugebauer, 2004). These data suggest that group I mGluRs in the CeA could be critical to nociceptive processing in this nucleus. However, the specific contributions of mGluR1 and mGluR5, as well as those of downstream regulators, are unknown.

mGluR1 and mGluR5 are expressed throughout the pain neuroaxis (Ryo et al., 1993; Romano et al., 1995) and have been identified as important molecular components of nociception (Bhave et al., 2001; Karim et al., 2001b; Varney and Gereau, 2002; Li and Neugebauer, 2004; Han and Neugebauer, 2005; Hu et al., 2007; Ansah et al., 2009). Activation of mGluR5 can lead to ERK1/2 (extracellular-signal regulated kinase 1/2) phosphorylation (activation) via the intracellular MAPK (mitogen-activated protein kinase) cascade (Karim et al., 2001a). This signaling cascade has been shown to be critical for sensitization of spinal dorsal horn neurons (Hu and Gereau, 2003; Hu et al., 2003), a mechanism underlying enhancement of pain-like behavior after peripheral inflammation (Karim et al., 2001a; Adwanikar et al., 2004). In the context of peripheral inflammation, activation of ERK in the CeA of mice occurs in a lateralized manner, with more ERK activation occurring in the right amygdala compared with the left (Carrasquillo and Gereau, 2008), and is necessary for 
inflammation-induced mechanical hypersensitivity (Carrasquillo and Gereau, 2007). Furthermore, activation of ERK in the amygdala induces pain-like behavior in the absence of any peripheral injury, a phenomenon that may have important implications for pain syndromes that are not associated with an identified tissue injury. However, at this point the role of mGluR5 in this process is unknown.

In the present study, we sought to test the hypothesis that mGluR5 activation and downstream ERK1/2 activation in the $\mathrm{CeA}$ are necessary and sufficient for nociceptive behavioral sensitization. Utilizing both pharmacological and genetic techniques, we demonstrate that right amygdala mGluR5 activation induces bilateral tactile hypersensitivity and that mGluR 5 activation, but not endocrine feedback, is required for the mechanical hypersensitivity induced by peripheral inflammation. We demonstrate that mGluR5-mediated hypersensitivity is functionally coupled to and dependent on ERK1/2 activation. Finally, we find that mGluR5 expression is greater in the right amygdala relative to the left amygdala.

\section{Materials and Methods}

Animals

All mouse protocols were in accordance with National Institutes of Health guidelines and were approved by the Animal Care and Use Committees of Washington University School of Medicine (St. Louis, MO). Male mice (all C57BL/6 background) were housed on a 12/12 h light/ dark cycle [lights on at zeitgeber time (ZT) 0] with ad libitum access to rodent chow and water. Unless otherwise stated, wild-type (WT) C57BL/6J (The Jackson Laboratory) male mice age 6-8 weeks were used for pharmacological studies.

$m G l u R 5^{K O}$. Conventional mGluR5 knock-out $\left(\mathrm{mGluR} 5^{\mathrm{KO}}\right)$ male mice have been described previously (Jia et al., 1998) and were obtained from The Jackson Laboratory. For pharmacological testing with mGluR $5^{\mathrm{KO}}$ mice, cannula verification was done as described below.

$G R^{C e A K O}$. Mice homozygous for the GRloxP allele were stereotaxically injected into bilateral CeAs with either lentiviral (LV) vector LV-Ef1 $\alpha$ Cre $\left(\mathrm{GR}^{\mathrm{CeAKO}}\right.$ ) or LV-Ef1 $\alpha$-GFP (control mice; where GFP is green fluorescent protein) as described previously (Kolber et al., 2008). Briefly, mice were anesthetized and mounted in a stereotaxic frame. A small hole was drilled over the right and left CeAs (coordinates: $1.25 \mathrm{~mm}$ anterior to bregma; $\pm 2.7 \mathrm{~mm}$ lateral to midline; $4.7 \mathrm{~mm}$ ventral to skull). A 32 gauge needle was lowered into the hole and left in place for $1 \mathrm{~min}$ before injection of virus. Infectious viral particles $\left(4 \times 10^{5}\right)$ were injected over 5 $\mathrm{min}$ and the needle was left in place for $5 \mathrm{~min}$ after injection. All testing in these mice occurred 2 wk after recovery from surgery. After testing, brains were sectioned to determine needle targeting and the percentage of NeuN-positive glucocorticoid receptor (GR)-expressing cells as a measure of GR disruption in the CeA and nearby BLA. It was previously determined that GR ${ }^{\mathrm{CeAKO}}$ mice have $34.8 \pm 1.97 \%$ NeuN-positive GRexpressing cells compared with $95.0 \pm 0.48 \%$ NeuN-positive GRexpressing cells in the CeA of control LV-GFP-injected mice (Kolber et al., 2008). No significant differences were observed in the BLA in either LV-Cre or LV-GFP-injected mice.

$m G l u R 5^{\text {CeAKO }}$. Mice homozygous for the mGluR5loxP allele (Xu et al., 2009) or WT littermates were used. All animals were injected in the right amygdala with recombinant lentiviral vector LV-Ef1 $\alpha$-Cre (LV-Cre) similarly as described previously (Kolber et al., 2008). Briefly, mice were anesthetized with a combination ketamine/xylazine anesthetic and mounted in a stereotaxic frame. A small hole was drilled over the right CeA (coordinates: $1.25 \mathrm{~mm}$ anterior to bregma; $2.7 \mathrm{~mm}$ lateral to midline; $4.7 \mathrm{~mm}$ ventral to skull). A 32-gauge needle was lowered into the hole and left in place for $1 \mathrm{~min}$ before injection of virus. Infectious viral particles $\left(4 \times 10^{5}\right)$ were injected over $5 \mathrm{~min}$ and the needle was left in place for $5 \mathrm{~min}$ after injection. All testing in these mice occurred $2 \mathrm{wk}$ after recovery from surgery. After testing, brains were sectioned to determine needle targeting and $1 \mathrm{~mm}$ diameter $\times 1 \mathrm{~mm}$ high punches were made of the amygdala in two adjacent sections to determine the amount of mGluR5 disrupted in floxed mice compared with WT mice injected with LV-Cre. See below for processing of tissue punches.

\section{Surgical procedure for cannula implantation}

Mice were deeply anesthetized with a combination ketamine/xylazine anesthetic and mounted in a stereotaxic frame. Stainless steel guide cannulas $(8 \mathrm{~mm}$ ) were implanted at the CeA (coordinates: $1.25 \mathrm{~mm}$ anterior to bregma; $\pm 2.70 \mathrm{~mm}$ lateral to midline; $4.2 \mathrm{~mm}$ ventral to skull). The guide cannula was affixed to the skull with two bone screws (Stoelting) and dental cement. An $8 \mathrm{~mm}$ stylet was inserted in the guide cannula to prevent clogging. Mice recovered for $6 \mathrm{~d}$ before further testing. At the end of experiments, brains were sectioned to verify cannula position and injection site.

\section{Intra-amygdala drug infusions}

Injection procedures. Microinjections were performed as described previously (Carrasquillo and Gereau, 2007). Briefly, injections were performed using a 32-gauge injection cannula that extended $0.5 \mathrm{~mm}$ beyond the tip of the guide cannula. The injection cannula was attached to flexible plastic tubing and a microliter syringe (Hamilton) was used to deliver drugs. A total volume of $0.3 \mu \mathrm{l}$ was infused over a period of $3 \mathrm{~min}$ and the injection cannula was kept in place for an additional $1 \mathrm{~min}$ to allow for drug infusion.

Drugs injected. DHPG (Tocris Bioscience) is a potent agonist that activates both mGluR5 and mGluR1. On the day of the experiment, DHPG was dissolved in artificial CSF (aCSF) containing the following (in mM): $25 \mathrm{NaHCO}_{3}, 122 \mathrm{NaCl}, 1.3 \mathrm{CaCl}_{2}, 1.2 \mathrm{MgSO}_{4}, 3 \mathrm{KCl}$, and $0.4 \mathrm{KH}_{2} \mathrm{PO}_{4}$, $\mathrm{pH} 7.35$, to a final stock solution of $5 \mathrm{~mm}$. Stock solution was diluted in aCSF or aCSF/DMSO to the final concentrations stated in the text. 2-Methyl-6-(phenylethynyl)pyridine hydrochloride (MPEP; Tocris Bioscience) is a selective noncompetitive antagonist of mGluR5. On the day of the experiment, MPEP was dissolved in aCSF to a final stock solution of $5 \mathrm{~mm}$. Stock solution was diluted in aCSF to final concentrations stated in the text. 1,4-Diamino-2,3-dicyano-1,4-bis(2-aminophenylthio) butadiene (U0126; Tocris Bioscience) was selected to inhibit ERK activation. Experiments with U0126 were compared with the-negative structural control analog 1,4-diamino-2,3-dicyano-1,4-bis(methylthio) butadiene (U0124). U0126 and U0124 (Tocris Bioscience) were dissolved as described previously (Carrasquillo and Gereau, 2007). U0126 and U0124 were dissolved first in 100\% DMSO to a $2 \times$ stock solution. Final dilutions were made to be $50 \%$ DMSO/50\% aCSF. Dosing of U0126 was determined from our previous work with this drug (Carrasquillo and Gereau, 2007, 2008). For experiments using combinations of drugs, individual drugs were dissolved at $2 \times$ the stated final concentration and then combined 1:1 with other drug. Unless otherwise stated, aCSF was used as a vehicle control.

\section{Behavioral testing}

All behavioral testing was performed by an experimenter blinded to pharmacological treatment and genotype and was done between ZT1 and ZT8. Mice were habituated (for $>2 \mathrm{~h}$ ) and tested in $25 \times 25 \times 35 \mathrm{~cm}$ ventilated Plexiglas enclosures with background white noise used to mask random noise. Mechanical sensitivity was measured using von Frey filaments (North Coast Medical) as described previously (Fu et al., 2001; Yang and Gereau, 2003). Each von Frey filament, starting with the smallest, was applied to the mouse hindpaw until bent at $30^{\circ}$ for $\sim 2 \mathrm{~s}$. The smallest filament that evoked a paw withdrawal response in at least three of the five trials was taken as the mechanical threshold for that trial. Three to five baseline measurements were taken from each hindpaw on the day before all drug or formalin experiments. The average withdrawal force was calculated individually for each paw as the baseline. Mechanical hypersensitivity was calculated by comparing withdrawal thresholds after drug/formalin to baseline withdrawal value. For DHPG, DHPG plus MPEP, and DHPG plus U0126 experiments, intra-amygdala drug infusions were performed $30 \mathrm{~min}$ before mechanical testing. In tests using formalin-induced mechanical hypersensitivity, $10 \mu \mathrm{l}$ of $2 \%$ formalin (Sigma) solution was injected subcutaneously in the plantar surface of the right hindpaw. The right hindpaw was chosen for formalin treatment because previous work from our laboratory (Carrasquillo and Gereau, 2007, 2008) and others (Ji and Neugebauer, 2009) has shown that 
A

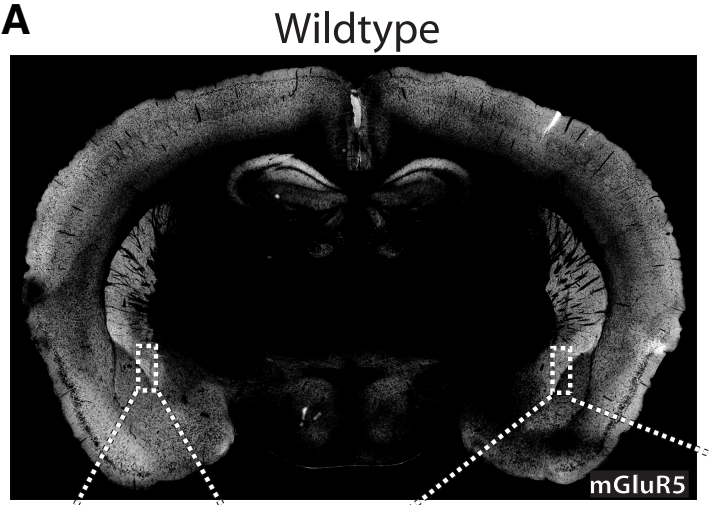

B

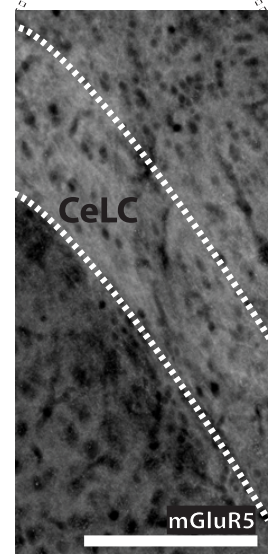

C
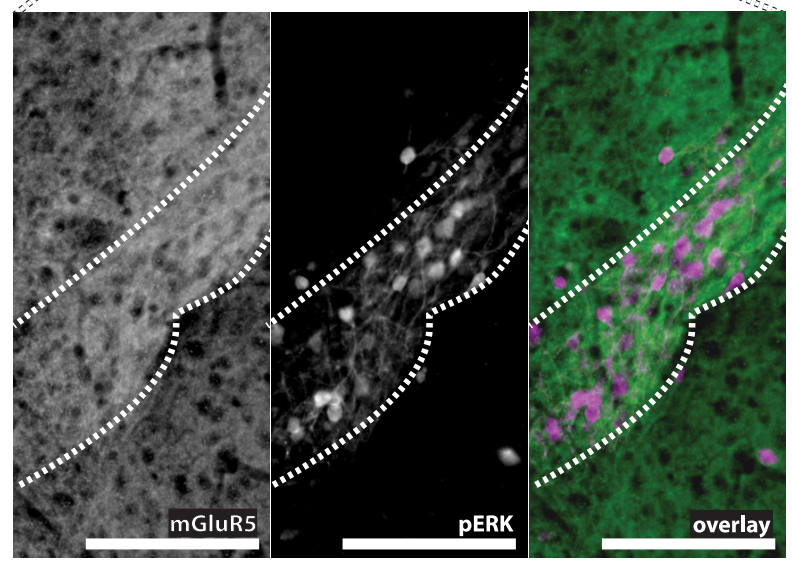

Figure 1. mGluR5 and phosphorylated ERK are expressed in the CeLC. A, Immunoreactivity showing mGluR5 expression (in white) in WT mice (mGluR5 control mice; left) or conventional mGluR5 ${ }^{\mathrm{KO}}$ mice (right). No positive signal was seen in mGluR5 ${ }^{\mathrm{KO}}$ sections. $\boldsymbol{B}, \boldsymbol{C}$, Magnified images demonstrate mGluR5 expression in the left ( $\boldsymbol{B}$; in white) and right CeLCs (C, left in white). $\boldsymbol{C}$, Additional panels for the right CeLC demonstrate that $\mathrm{mGluR5}$ (left panel, in white; right panel, in green) and phosphorylated ERK (middle panel, in white; right panel, in magenta) are expressed in the CeLC of WT mice. Scale bars, $200 \mu \mathrm{m}$.
7.4, 1 mм EDTA, 1 mм sodium pyrophosphate, $25 \mu \mathrm{g} / \mathrm{ml}$ aprotinin, $25 \mu \mathrm{g} / \mathrm{ml}$ leupeptin, 1 $\mu \mathrm{g} / \mathrm{ml}$ microcystein, $1 \mathrm{~mm}$ sodium orthovanadate, and $100 \mu \mathrm{M}$ phenylmethylsulfonyl fluoride; Sigma) using a Dounce homogenizer. Protein concentrations were determined using the BCA protein assay kit (Pierce Biotechnology). The levels of ERK activation in the amygdala were measured by Western blotting using antibodies specific for phosphorylated ERK (pERK) and total ERK. Total protein $(5 \mu \mathrm{g})$ for amygdala homogenates was run using $4-12 \%$ SDS-PAGE (Invitrogen) and transferred to nitrocellulose membranes (Whatman). Blots were blocked in Odyssey blocking buffer (Licor) for $1 \mathrm{~h}$ and then coincubated in mouse anti-p44/42 ERK (1:1000, Cell Signaling Technology, Beverly, MA) and rabbit antiphospho-p44/42 ERK (1:1000; Cell Signaling Technology) primary antibodies in Odyssey buffer with $0.1 \%$ Tween 20 (Sigma) for $1 \mathrm{~h}$ at room temperature (RT). After washing in TBS with $0.1 \%$ Tween 20, blots were incubated in goat anti-rabbit IR 800 (1:20,000; Rockland) and goat anti-mouse Alexa 680 (1:20,000 Invitrogen) for $1 \mathrm{~h}$ at RT. Blots were washed and scanned using an Odyssey scanner (Licor). Densitometry of bands corresponding to ERK1 (p44) and ERK2 (p42) was performed using Odyssey v3.0 software (Licor).

Effect of MPEP on formalin-induced ERK1/2 activation. To determine the effects of MPEP on formalin-induced ERK1/2 activation, intraright amygdala drug infusion was performed $2 \mathrm{~h}$ after formalin injection and brains were removed $60 \mathrm{~min}$ after drug infusion, which corresponds to $3 \mathrm{~h}$ after formalin injection in the paw. Brains were sectioned into 1-mmthick coronal sections using an acrylic brain matrix (Stoelting) From the two appropriate sections, amygdala punches (two per side per

inflammation-induced right CeA activation occurs independently of the side of peripheral inflammation (i.e., right or left side of body). For nonpharmacological experiments with mGluR5 ${ }^{\mathrm{KO}}$, mGluR5 ${ }^{\mathrm{CeAKO}}$, and GR ${ }^{\text {CeAKO }}$ mice, mechanical sensitivity was measured $3 \mathrm{~h}$ following intraplantar formalin injection. To determine the effects of MPEP on formalin-induced mechanical hypersensitivity, intra-amygdala drug infusion was performed $2 \mathrm{~h}$ after formalin injection and mechanical thresholds were measured $1 \mathrm{~h}$ after intra amygdala drug infusion, which corresponds to $3 \mathrm{~h}$ after formalin injection in the paw.

The formalin test to measure spontaneous behaviors following formalin injection was performed as described previously (Bhave et al., 2001). mGluR5 ${ }^{\mathrm{CeAKO}}$ and control mice were videotaped following intradermal formalin injection and analyzed offline for nociceptive behavior (defined as licking, lifting, and flinching of the injected paw) in 5 min bins. The first phase of spontaneous behavior was defined as $0-10 \mathrm{~min}$ after formalin, and then the second phase of testing was defined as 10-35 min after formalin injection.

\section{Western blotting}

All plots of Western quantification are normalized to the control (e.g., vehicle) left amygdala level of protein and are expressed as "fold control."

DHPG and DHPG/U0126 ERK1/2 activation. Following intraamygdala infusion of $0.1 \mathrm{nmol}$ of DHPG alone (compared with vehicle) or DHPG plus U0126 (compared with DHPG plus U0124), brains were removed and sectioned into 1-mm-thick coronal sections using an acrylic brain matrix (Stoelting). From the two appropriate sections, amygdala punches (two per side per animal) were obtained using a custom-made $1 \mathrm{~mm}$ punch tool. Samples were frozen on dry ice and then homogenized in ice-cold homogenization buffer $(20 \mathrm{~mm}$ Tris- $\mathrm{HCl}, \mathrm{pH}$ animal) were obtained using a custom-made $1 \mathrm{~mm}$ punch tool. Activated ERK1/2 was analyzed as described above by Western blot.

Protein expression in $m G l u R 5^{K O}$ and $m G l u R 5^{C e A K O}$ mice. Brains were removed from mGluR5 ${ }^{\mathrm{KO}}$ mice (compared with WT mice) or mGluR5 ${ }^{\text {CeAKO }}$ mice (compared with LV-Cre-injected WT mice) and sectioned into $1 \mathrm{~mm}$-thick coronal sections. From the two appropriate sections, amygdala punches (two per side per animal) were processed as described above with ice-cold homogenization buffer (20 mM Tris-HCl, $\mathrm{pH}$ 7.4, 1 mм EDTA, 1 mм sodium pyrophosphate, $25 \mu \mathrm{g} / \mathrm{ml}$ aprotinin, $25 \mu \mathrm{g} / \mathrm{ml}$ leupeptin, and $100 \mu \mathrm{M}$ phenylmethylsulfonyl fluoride). The levels of mGluR5 or GR in the left or right amygdala were measured by Western blotting using antibodies specific for mGluR5 or GR and the loading control protein $\beta$-tubulin. Total protein $(3-5 \mu \mathrm{g})$ for amygdala homogenates was run using $4-12 \%$ SDS-PAGE and transferred to nitrocellulose membranes. For mGluR5 Western blotting, blots were blocked in Odyssey blocking buffer for $1 \mathrm{~h}$ and then coincubated in mouse anti$\beta$-tubulin (1:10,000; Sigma) and rabbit anti-mGluR5 (1:1000; Millipore) primary antibodies in Odyssey buffer with $0.1 \%$ Tween 20 for $1 \mathrm{~h}$ at RT. For GR Western blotting, blots were blocked in Odyssey blocking buffer for $1 \mathrm{~h}$ and then coincubated in anti- $\beta$-tubulin and rabbit anti-GR (1: 1000; Santa Cruz Biotechnology) primary antibodies in Odyssey buffer with $0.1 \%$ Tween 20 overnight at $4^{\circ} \mathrm{C}$. After washing in TBS with $0.1 \%$ Tween 20, blots were incubated in goat anti-mouse IR800 (1:20,000) and goat anti-rabbit Alexa $680(1: 20,000)$ for $1 \mathrm{~h}$ at RT. Blots were washed and scanned using an Odyssey scanner. Densitometry of bands corresponding to mGluR5/GR and $\beta$-tubulin was performed using Odyssey software. Each mGluR5 or GR value was divided by the pixel value for that 
sample's $\beta$-tubulin value and then normalized to the left amygdala control.

\section{Immunohistochemistry}

DHPG-induced ERK activation. Thirty minutes after intra-amygdala infusion of $0.1 \mathrm{nmol}$ of DHPG (compared with vehicle), mice were deeply anesthetized with $2.5 \%$ Avertin anesthesia and then perfused transcardially with PBS $\left(37^{\circ} \mathrm{C}\right)$, followed by $100 \mathrm{ml}$ of ice-cold $4 \%$ paraformaldehyde (PFA) solution in PBS. The brain was dissected and postfixed in PFA overnight at $4^{\circ} \mathrm{C}$. After cryoprotection in $30 \%$ sucrose, coronal sections $(30 \mu \mathrm{m})$ were obtained on a cryostat and stored in PBS at $4^{\circ} \mathrm{C}$ until immunostaining. Sections were rinsed in PBS, incubated in $10 \% \mathrm{MeOH} / 0.3 \% \mathrm{H}_{2} \mathrm{O}_{2}$ in PBS for $30 \mathrm{~min}$ at RT, and blocked in $1 \%$ normal goat serum (NGS) (Vector Laboratories) with $0.02 \%$ Triton X-100 for $1 \mathrm{~h}$ at RT. Sections were incubated overnight at $4^{\circ} \mathrm{C}$ in rabbit antiphospho-p44/42 ERK antibody (1:1000; Cell Signaling Technology) in blocking solution. Sections were rinsed in PBS with $0.2 \%$ Triton $\mathrm{X}-100$ and incubated in goat anti-rabbit biotinylated secondary antibody (1:200; Vector Laboratories) in blocking solution for $120 \mathrm{~min}$ at RT. Sections were rinsed in PBS with $0.2 \%$ Triton X-100 and incubated in an avidinbiotin complex (Vector Laboratories) for 60 min at RT. Sections were rinsed in PBS and incubated in a Cy-3-conjugated tyramide signal amplification reagent (PerkinElmer). Immunohistochemical sections were wet mounted and visualized using a Nikon Eclipse 80i fluorescent microscope. Note that we typically see some amount of pERK immunofluoresence in naive animals (Carrasquillo and Gereau, 2007).

$m G l u R 5$ and ERK in WT and $m G l u R 5^{K O}$ mice. Mice were deeply anesthetized and processed as above. Sections were first stained for phosphorylated ERK as described above. Following ERK staining, sections were then blocked in $3 \%$ NGS with $0.3 \%$ Triton X-100 for $1 \mathrm{~h}$ at RT. Sections were incubated overnight at $4^{\circ} \mathrm{C}$ in anti-mGluR5 antibody (1:1500) in blocking solution. Sections were rinsed in PBS with $0.2 \%$ Triton X-100 and incubated in goat anti-rabbit Alexa 488-conjugated secondary antibody (1:200, Invitrogen) in blocking solution for $60 \mathrm{~min}$ at RT. Immunohistochemical sections were wet mounted and visualized using a Nikon Eclipse 80i fluorescent microscope.

\section{Data analysis}

Results are expressed as means \pm SEM. Unpaired Student's $t$ tests were used to compare pairs of means. To compare lateralization of protein, paired Student's $t$ tests were used to compare two means from the same group of mice (e.g., right versus left amygdala protein expression in control mice). In cases of two independent variables [e.g., genotype and treatment (preformalin and postformalin)], two-way ANOVA with repeated measures was used followed by Bonferroni post hoc tests when significant main effects were found. A value of $p \leq 0.05$ was considered statistically significant for all statistical comparisons. All statistical comparisons were done with Prism 5 software (GraphPad).

\section{Results}

mGluR5 and activated ERK1/2 are expressed in the CeLC

We evaluated mGluR5 in the brains of WT and conventional mGluR5 knock-out mice under naive conditions (Jia et al., 1998) (Fig. 1A). mGluR5 expression in WT mice is highest in the hippocampus, striatum, and a small section of the amygdala, but is diffusely expressed throughout the parenchyma (Fig. 1A, left). No positive immunohistochemical signal was detected in the brains of mGluR $5{ }^{\mathrm{KO}}$ mice (Fig. $1 \mathrm{~A}$, right). In WT mice, mGluR 5
A

Left Paw

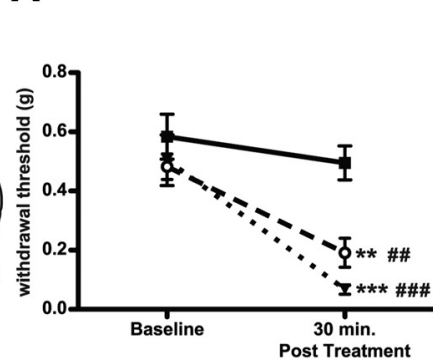

C Left Paw D

C Left Paw D

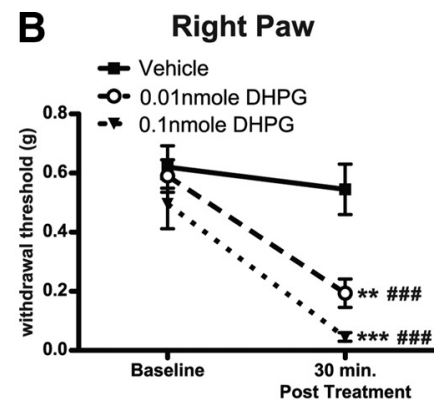

D Right Paw
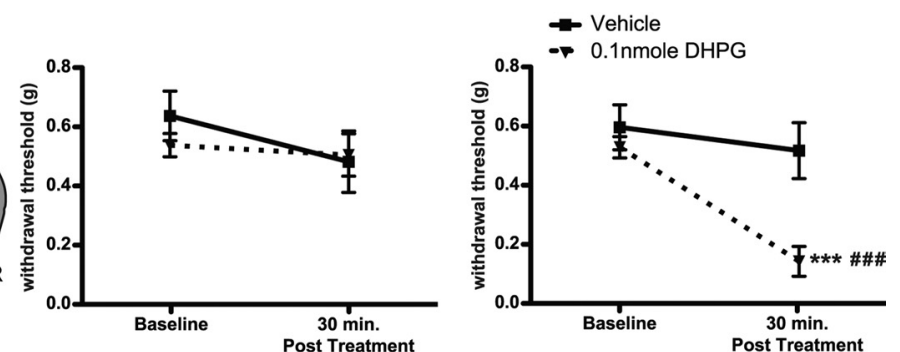

Figure 2. Activation of amygdala mGluR5 induces mechanical hypersensitivity. $A, B, D H P G$, a selective group I mGluR agonist, Reated-measures ANOVA with Bonferroni post-test: ${ }^{* *} p<0.01$, ${ }^{* *} p<0.001$, compared with vehicle-treated group at 1, ${ }^{\# \#} p<0.001$, compared with baseline for specified group.

is expressed in the CeLC, the putative nociceptive amygdala (Fig. $1 B, C$ ), with activated ERK1/2 (Fig. 1C). After identifying the presence of mGluR5 in the CeLC, we tested the hypothesis that mGluR5 activation in the amygdala is sufficient to induce mechanical hypersensitivity.

\section{Intra-amygdala mGluR5 activation induces mechanical hypersensitivity}

We used the von Frey test to determine whether activation of CeA group I mGluRs was sufficient to induce peripheral mechanical hypersensitivity. The von Frey test is an established method for determining mechanical sensitivity in mice (Fu et al., 2001). Baseline withdrawal sensitivity measurements were performed in WT mice, and 1 day later either DHPG $(0.1$ or $0.01 \mathrm{nmol})$ or vehicle was infused into the right amygdala via a preimplanted cannula ( $0.3 \mu \mathrm{l}$ over a $3 \mathrm{~min}$ period). Withdrawal to mechanical stimulation was assessed $30 \mathrm{~min}$ postinfusion. Infusion of DHPG into the CeA significantly decreased mechanical withdrawal thresholds in both hindpaws (Fig. 2A,B) compared with baseline values and postvehicle thresholds.

Previous work has found that intracellular signaling cascades critical to the modulation of mechanical hypersensitivity are functionally lateralized to the right amygdala (Carrasquillo and Gereau, 2007, 2008). To test whether this was also true for group I mGluRs, we next examined the effects of left amygdala DHPG infusion $(0.1 \mathrm{nmol})$ on mechanical withdrawal thresholds. Whereas right amygdala infusion of DHPG induced bilateral hypersensitivity, we found that left amygdala infusion induced hypersensitivity in only the contralateral (right) hindpaw (Fig. 2C,D).

Subsequently, our studies focused on manipulations of the right amygdala because previous work from our laboratories (Carrasquillo and Gereau, 2007, 2008) and others (Ji and Neugebauer, 2009) has shown that pain-related right CeA activation 
A

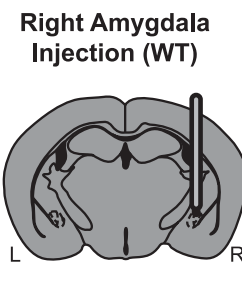

Right Amygdala Injection (mGluR5 ${ }^{\text {Ko }}$

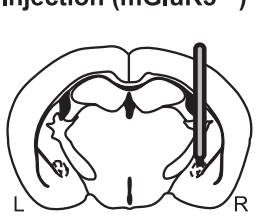

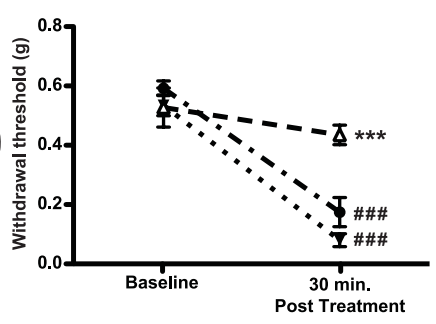

C

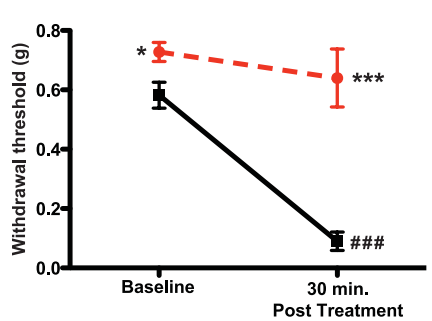

B

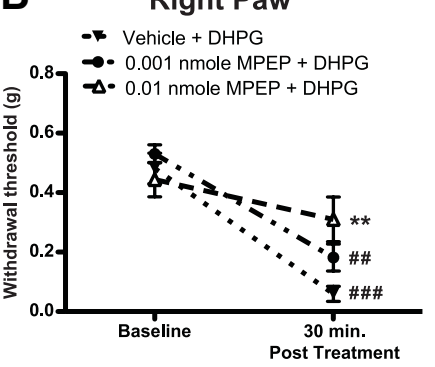

D

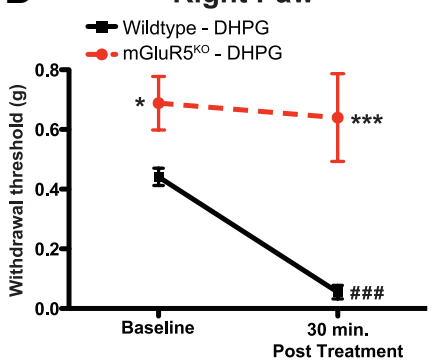

Figure 3. mGluR5 is required for intra-amygdala DHPG-induced mechanical hypersensitivity. $A, B, M P E P$ (an mGluR5 antagonist) $(0.001 \mathrm{nmol}, n=6 ; 0.01 \mathrm{nmol}, n=6)$, but not vehicle $(n=7)$, coinfused with DHPG $(0.1 \mathrm{nmol})$ into the right amygdala blocks mechanical hypersensitivity induced by DHPG in the left $(\boldsymbol{A})$ and right $(\boldsymbol{B})$ paws. $\boldsymbol{C}, \boldsymbol{D}, \mathrm{DHPG}$ injected in the right amygdala induces mechanical hypersensitivity in WT mice $(n=6)$ but not mGluR5 ${ }^{\mathrm{K} 0}$ mice $(n=5)$. Baseline withdrawal thresholds in mGluR5 ${ }^{\mathrm{KO}}$ mice are higher than those of control mice. Gray area in brain illustration is representative of WT mGluR5 expression; white area in brain illustration is representative of where mGluR5 is deleted. Data are expressed as mean \pm SEM. Repeatedmeasures ANOVA with Bonferroni post-test: ${ }^{*} p<0.05,{ }^{* *} p<0.01,{ }^{* * *} p<0.001$, compared with vehicle plus DHPG-treated group $(\boldsymbol{A}, \boldsymbol{B})$ or mGluR5 WT mice $(\boldsymbol{C}, \boldsymbol{D})$ at specified time point; ${ }^{\# \#} p<0.01, \# \# p<0.001$, compared with baseline for specified group.

occurs independently of the side of injury. To determine whether the effects of right amygdala DHPG were due to specific activation of mGluR5, the noncompetitive mGluR5 antagonist MPEP $(0.001 \mathrm{nmol}$ or $0.01 \mathrm{nmol})$ was coinfused with DHPG $(0.1 \mathrm{nmol})$ into the right amygdala of WT mice before testing. Mice coinfused with $0.01 \mathrm{nmol}$ of MPEP and DHPG exhibited no changes from baseline and significantly higher mechanical withdrawal thresholds in both hindpaws than did mice coinfused with vehicle and DHPG (Fig. $3 A, B$ ). The effects of MPEP were dose dependent, as 0.001 MPEP coinfused with DHPG failed to inhibit DHPG-induced hypersensitivity. In a separate experiment, MPEP $(0.01 \mathrm{nmol})$ alone did not significantly affect withdrawal thresholds compared with those of vehicle-treated mice (left paw withdrawal threshold: vehicle $n=60.43 \pm 0.07 \mathrm{~g}$ vs $0.01 \mathrm{nmol}$ of MPEP $n=50.35 \pm 0.05 \mathrm{~g}$; Student's $t$ test, $p=0.41$; right paw withdrawal threshold: vehicle $n=60.39 \pm 0.06 \mathrm{~g}$ vs $0.01 \mathrm{nmol}$ of MPEP $n=50.39 \pm 0.07 \mathrm{~g}$; Student's $t$ test, $p=0.99)$. This suggests that the effects of MPEP on DHPG-induced hypersensitivity are not attributable to MPEP-induced alterations in mechanical sensitivity in the absence of DHPG. Together, all of these results demonstrate the necessity of amygdala mGluR5 in DHPG-induced mechanical hypersensitivity.

In addition to pharmacological testing, we used mGluR $5^{\mathrm{KO}}$ mice to test for the necessity of mGluR5 in DHPG-induced mechanical hypersensitivity. Baseline withdrawal thresholds were higher in mGluR5 ${ }^{\mathrm{KO}}$ mice compared with those of WT littermates (Fig. 3C,D). Following baseline testing, DHPG $(0.1 \mathrm{nmol})$ was infused into the right amygdalas of all mice. Whereas infusion of DHPG induced robust bilateral hypersensitivity in WT mice, we found that infusion of DHPG into mGluR5 ${ }^{\mathrm{KO}}$ mice failed to induce any significant mechanical hypersensitivity in either paw (Fig. 3C,D). Overall, these data demonstrate the ne- cessity of mGluR5 in DHPG-induced mechanical hypersensitivity.

\section{mGluR5 activation in the right amygdala results in ERK1/2 activation} Thus far, we have demonstrated that mGluR5 activation in the amygdala is sufficient to induce mechanical hypersensitivity in uninjured mice. To evaluate the downstream signaling components of mGluR5 activation in the amygdala, we tested whether group I mGluR activation would induce ERK1/2 activation. Representative sections show activated ERK1/2 in the amygdala of mice infused with DHPG $(0.1 \mathrm{nmol})$ or vehicle into the right amygdala (Fig. $4 A$ ). In a separate cohort of mice, animals were injected with either DHPG $(0.1 \mathrm{nmol})$ or vehicle alone and evaluated by Western blotting for amygdalar ERK1 or ERK2 activation (Fig. 4B). Quantification revealed that right amygdala DHPG infusion induced a significant increase in ERK1 (pERK1/totalERK1 expressed as fold control left amygdala) (Fig. 4C) and ERK2 activation (pERK2/ totalERK2 expressed as fold control left amygdala) (Fig. 4D) in the right amygdala compared with samples taken from the left amygdala of DHPG-injected mice and samples from vehicle-injected animals.

Given that ERK1/2 is activated by DHPG, we next asked whether ERK activation might be necessary for the observed right amygdala DHPG-induced mechanical hypersensitivity. DHPG $(0.1 \mathrm{nmol}$ in aCSF $)$ was coinfused into the right amygdala of WT mice with either a MEK1/2 inhibitor (U0126; $1.5 \mathrm{nmol}$ in DMSO) or an inactive control analog (U0124; $1.5 \mathrm{nmol}$ in DMSO) $30 \mathrm{~min}$ before von Frey behavioral testing. DHPG infusion resulted in significantly decreased paw withdrawal thresholds, which were partially reversed by coinfusion with U0126 but not the inactive analog U0124 (Fig. 4E,F). At this dose of U0126, we have previously shown no differences in mechanical sensitivity between U0126- and vehicle-treated mice (Carrasquillo and Gereau, 2007), suggesting that the observed effects of U0126 on DHPGinduced mechanical hypersensitivity are not caused by U0126mediated alterations in baseline sensitivity in the absence of DHPG.

Following behavioral testing, we evaluated whether MEK1/2 inhibition with U0126 would block DHPG-induced ERK1/2 activation. ERK1 and ERK2 activation after DHPG coinfusion with either U0124 or U0126 is shown in a representative Western blot (Fig. 4G). Quantification revealed that DHPG-induced ERK1/2 activation in the right amygdala was significantly decreased with coinfusion of U0126 compared with coinfusion of U0124 (Fig. 4H).

\section{Pharmacological blockade of mGluR5 inhibits formalin-} induced behavioral hypersensitivity and ERK1/2 activation We have demonstrated that activation of mGluR5 in the amygdala is sufficient to induce peripheral mechanical hypersensitivity in the absence of any injury or painful stimulus. We next sought to test the hypothesis that activation of mGluR5 in the right amygdala is necessary for the full expression of nociceptive be- 
havior following formalin-induced peripheral inflammation (Fu et al., 2001; Carrasquillo and Gereau, 2007).

To test whether blocking mGluR5 activation in the right amygdala has an effect on this nociceptive response, WT mice were given right paw intraplantar injections of formalin ( $2 \%$ in saline) and $2 \mathrm{~h}$ later were treated with either MPEP $(0.01$ $\mathrm{nmol}$ ) or vehicle via right intra-amygdala infusion. In all animals tested, withdrawal thresholds to mechanical stimuli in both paws were significantly reduced $1 \mathrm{~h}$ after formalin injection. At $3 \mathrm{~h}$, mechanical withdrawal thresholds after MPEP infusion were significantly higher in both paws compared with withdrawal thresholds in vehicle-infused mice (Fig. 5A,B). Furthermore, MPEP infusion significantly increased withdrawal thresholds in both paws compared with $1 \mathrm{~h}$ postformalin values and returned withdrawal thresholds in the noninjected (left) paw to a level that was not significantly different from the preformalin baseline (Fig. 5A). These results suggest that mGluR5 in the CeA is necessary for the full behavioral response to intraplantar formalin.

Previous work has demonstrated that formalin induces a selective activation of ERK1/2 in the right CeLC (Carrasquillo and Gereau, 2007). To test whether mGluR5 activation in the right amygdala is necessary for this inflammation-induced change, we evaluated formalin-induced ERK1/2 activation following amygdalar infusion of MPEP or vehicle. WT mice were given right paw intraplantar injections of formalin and $2 \mathrm{~h}$ later were administered with either MPEP $(0.01 \mathrm{nmol})$ or vehicle via right intra-amygdala infusion. Comparing the right amygdala between the two groups, we found a significant decrease in ERK1 and ERK2 activation $3 \mathrm{~h}$ after formalin in the MPEP-treated group compared with the vehicle group (Fig. 5C,D), suggesting that mGluR5 is necessary for formalin-induced ERK1/2 activation in the amygdala.

Although mGluR5 inhibition in the right amygdala was sufficient to reverse formalin-induced mechanical hypersensitivity, we also tested whether blocking mGluR5 activation in the left amygdala might have an effect on this nociceptive response. WT mice were given right paw intraplantar injections of formalin $(2 \%$ in saline) and treated $2 \mathrm{~h}$ later with either MPEP $(0.01 \mathrm{nmol})$ or vehicle via left intra-amygdala infusion. In all animals tested, withdrawal thresholds to mechanical stimuli in both paws were significantly reduced at both 1 and $3 \mathrm{~h}$ after formalin injection (Fig. $5 E, F$ ). Interestingly, in
A DHPG-Injected
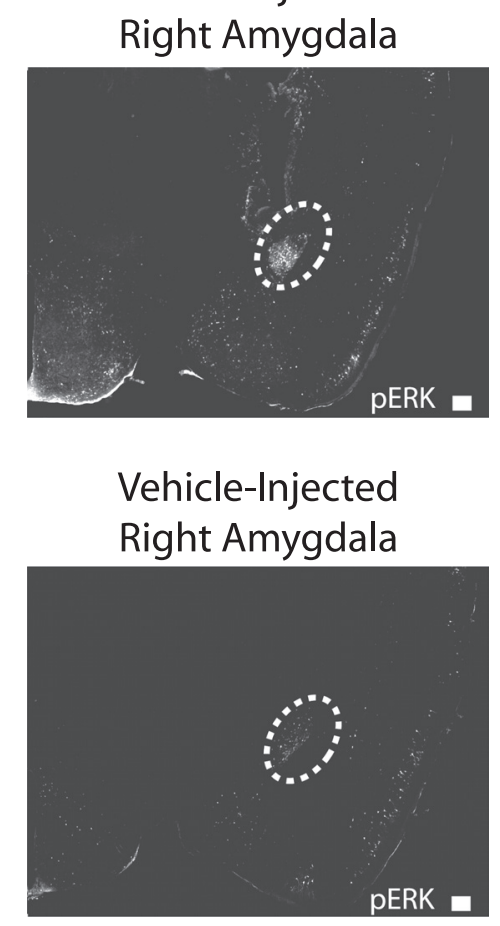

E

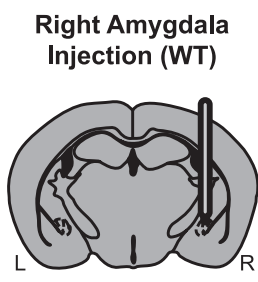

G

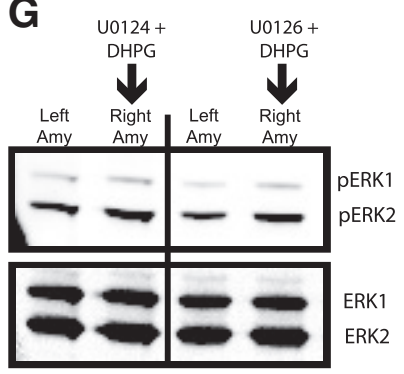

B

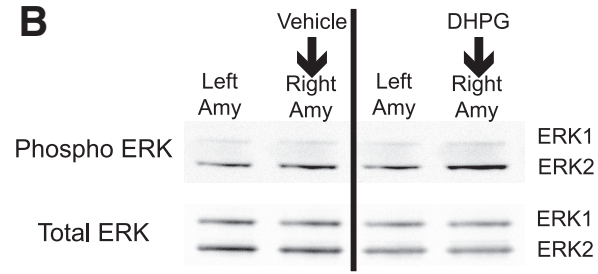

C ERK1 Vehicle $\square$ DHPG

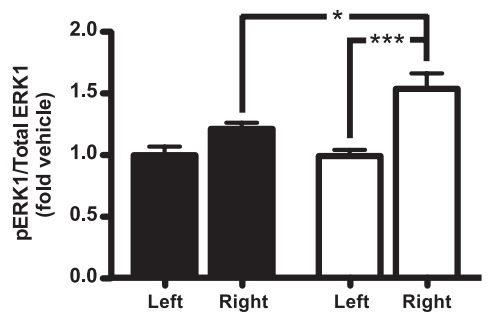

D ERK2

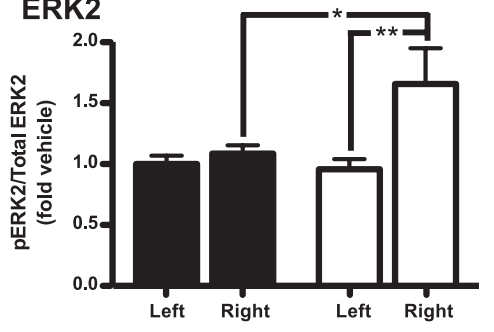

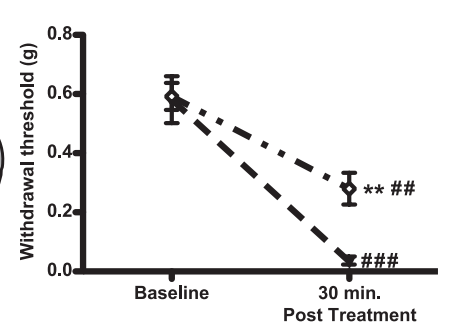

$\mathbf{F}$
H

\section{pERK1 \& pERK2 Right Amygdala}

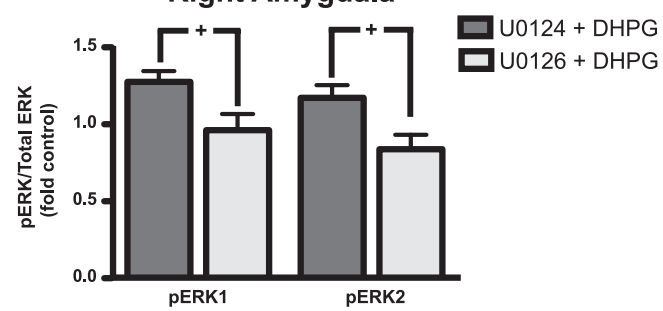

Figure 4. DHPG and ERK activation in the amygdala. $\boldsymbol{A}$, Representative sections showing immunofluoresence (white) for phosphorylated ERK1/2 in the amygdala [white dotted-line: top, $0.1 \mathrm{nmol}$ of DHPG injected $30 \mathrm{~min}$ before kill; bottom, vehicle (aCSF) injected 30 min before kill]. $\boldsymbol{B}$, Representative Western blot showing phosphorylated (Phospho) ERK1 and ERK2 bands (top) and total ERK1 and ERK2 (bottom) from mice injected in the right amygdala (Amy) with either vehicle $(n=8)$ or DHPG $(0.1 \mathrm{nmol}, n=8)$ before being killed. $C, D$, Quantification of Western blots showing increased activation of ERK by DHPG compared with vehicle. C, Activated ERK1 is increased in the right amygdala of DHPG-treated mice compared with the left amygdala of DHPG-injected mice and vehicle-injected right amygdala samples. D, Activated ERK2 is increased in the right amygdala after DHPG injection compared with left amygdala ofDHPG-injected mice and vehicle-injected right amygdala samples. $\boldsymbol{E}, \boldsymbol{F}$, Right amygdala coinfusion of $0.1 \mathrm{nmol}$ of DHPG with the MEK1/2 inhibitor U0126 (1.5 nmol, $n=6$ ) induces reduced mechanical hypersensitivity compared with coinfusion of DHPG plus U0124 (inactive control analog of U0126, $n=$ 5 ) in both the left $(\boldsymbol{E})$ and right $(\boldsymbol{F})$ paws. $\boldsymbol{G}$, Representative Western blot showing phosphorylated ERK1 and ERK2 bands (top) and total ERK1 and ERK2 (bottom blot) from mice injected in the right amygdala with DHPG and U0124 $(n=5)$ or DHPG and U0126 $(n=6)$ before being killed. $\boldsymbol{H}$, Quantification of right amygdala tissue sample Western blot showing reduced ERK1 and ERK2 phosphorylation in mice injected with U0126 plus DHPG compared with mice injected with U0124 plus DHPG. Gray area in brain illustration is representative of WT mGluR5 expression. Scale bars, $200 \mu \mathrm{m}$. Data are expressed as mean \pm SEM. Graphs of Western data are normalized to control left amygdala protein expression. Repeated-measures ANOVA with Bonferroni post-test: ${ }^{*} p<0.05,{ }^{* *} p<0.01,{ }^{* * *} p<0.001$, compared with specified sample $(\boldsymbol{C}, \boldsymbol{D})$ or other group at indicated time point $(\boldsymbol{E}, \boldsymbol{F}) ;{ }^{\#} p<0.05,{ }^{\#} p<0.01,{ }^{\# \# \#} p<0.001$, compared with baseline for specified group; unpaired Student's t test: ${ }^{+} p<0.05$. 

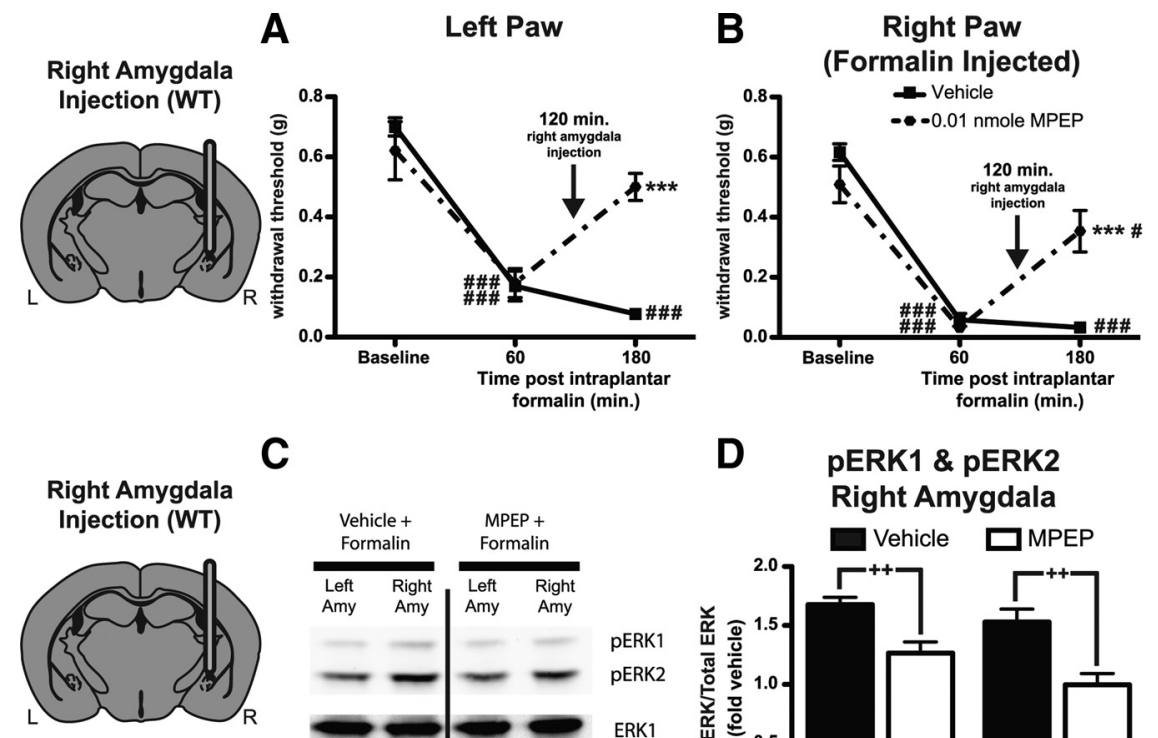

C

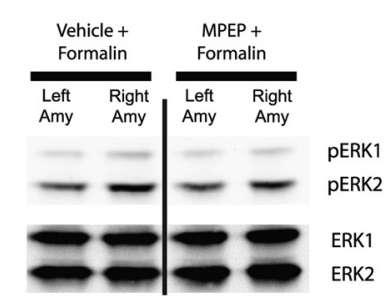

D

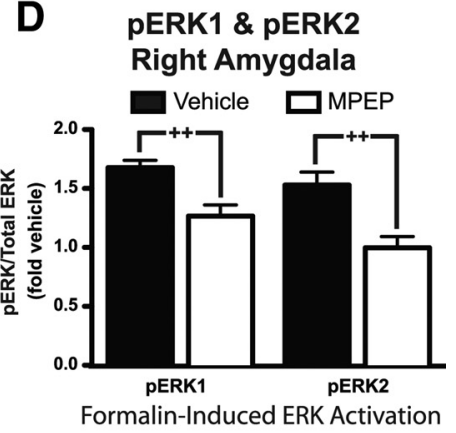

E
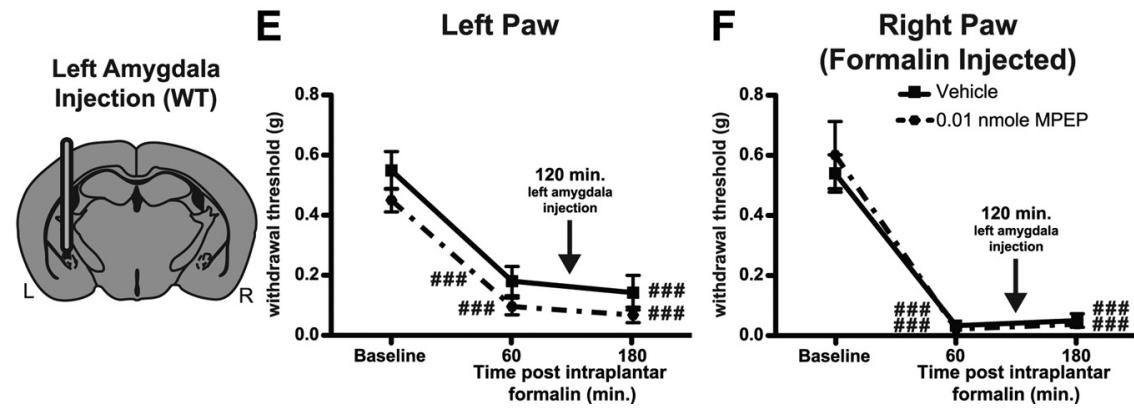

Figure 5. mGluR5 activation is necessary for formalin-induced mechanical hypersensitivity and ERK1/2 activation. $\boldsymbol{A}-\boldsymbol{F}$, Mice are injected in the right paw with formalin at time $0 \mathrm{~min} . \boldsymbol{A}, \boldsymbol{B}$, Intra-right amygdala MPEP $(0.01 \mathrm{nmol}, n=6$ at $120 \mathrm{~min})$ reverses mechanical hypersensitivity in the noninjected paw $(\boldsymbol{A})$ and reduces hypersensitivity in the injected paw $(\boldsymbol{B})$ compared with predrug measurements (at $60 \mathrm{~min}$ ) and baseline values. In addition, MPEP-treated mice exhibit increased withdrawal thresholds compared with those of intra-right amygdala vehicle-treated mice $(n=6) . \boldsymbol{C}, \boldsymbol{D}$, Intra-right amygdala MPEP $(0.01 \mathrm{nmol}$ at $120 \mathrm{~min}$ after intraplantar formalin) reverses formalin-induced ERK1/2 activation in the right amygdala (Amy). C, Representative Western blot showing phosphorylated ERK1 and ERK2 bands (top) and total ERK1 and ERK2 (bottom) from mice injected in the right amygdala with MPEP $(n=8)$ or vehicle $(n=8) 60$ min before kill ( 180 min after intraplantar formalin). D, Quantification of right amygdala tissue sample Western blots showing reduced ERK1 and ERK2 phosphorylation in mice injected with MPEP compared with samples from mice injected with vehicle. $\boldsymbol{E}, \boldsymbol{F}$, Intra-left amygdala MPEP ( $0.01 \mathrm{nmol}, n=5$ at $120 \mathrm{~min})$ does not reverse mechanical hypersensitivity in either the noninjected $(\boldsymbol{E})$ or injected paw $(\boldsymbol{F})$. Furthermore, left-amygdala MPEP-treated mice do not exhibit different withdrawal thresholds compared with those of intra-left amygdala vehicle-treated mice $(n=6)$ at any time point after formalin injection. Gray areas in brain illustrations are representative of WT mGluR5 expression. Data are expressed as mean \pm SEM. Graphs of Western data are normalized to control left amygdala protein expression. Repeated-measures ANOVA with Bonferroni post-test: ${ }^{* * *} p<0.001$, compared with vehicle-treated group at specified time point; ${ }^{\#} p<0.05,{ }^{\# \# \#} p<0.001$, compared with baseline for specified group; unpaired Student's $t$ test: ${ }^{++} p<0.01$.

contrast to our results of MPEP infusion into the right amygdala, MPEP infusion into the left amygdala did not induce changes in withdrawal thresholds compared with vehicle-treated mice. Together, these results suggest that mGluR5 in the right CeA only is necessary for the full mechanical behavioral response to intraplantar formalin.

\section{Genetic disruption of mGluR5 blocks formalin-induced mechanical hypersensitivity}

The specific role for mGluR5 in formalin-induced mechanical hypersensitivity was also verified by testing mGluR5 ${ }^{\mathrm{KO}}$ mice and WT littermates in the von Frey test. In accordance with our base- line results above, withdrawal thresholds for mGluR5 ${ }^{\mathrm{KO}}$ mice were significantly greater than those of WT littermates in the right paw (Fig. 6B). Interestingly, intraplantar formalin induced mechanical hypersensitivity in both hindpaws of WT mice but only in the injected (right) hindpaw of mGluR $5^{\mathrm{KO}}$ mice (Fig. $6 A, B$ ). Furthermore, withdrawal thresholds of mGluR $5^{\mathrm{KO}}$ mice were significantly greater than those of WT littermates for both paws $3 \mathrm{~h}$ after formalin injection.

To confirm deletion of mGluR5 in mGluR5 ${ }^{\mathrm{KO}}$ mice, amygdala tissue was probed for mGluR5 expression using Western blotting. Representative blots in Figure $6 C$ clearly show an absence of mGluR5 signal in KO mice compared with WT littermates. In addition, as ERK is preferentially activated in the right amygdala of WT mice during inflammation (Carrasquillo and Gereau, 2007, 2008), WT amygdala samples were probed to see whether mGluR5 protein expression might differ between the left and right amygdalas. mGluR5 expression is significantly higher in the right amygdala relative to the left (Fig. $6 C$ ) (paired Student's $t$ test $p=0.021)$. We also tested to see whether there might be a lateralization of total ERK1/2 in the amygdala of WT and mGluR5 ${ }^{\mathrm{KO}}$ mice. Comparing right amygdala ERK1 or ERK2 expression relative to left amygdala expression, we found no significant lateralization of either isoform for either genotype and no differences between genotypes (data not shown).

\section{Targeted disruption of amygdalar endocrine feedback does not inhibit formalin-induced mechanical hypersensitivity}

An important question in understanding the amygdala's role in processing persistent inflammatory pain is whether nociceptive behavior is influenced by endocrine inputs to the amygdala. A component of the physiological response to formalin in mice is an activation of the hypothalamic-pituitaryadrenal (HPA) axis leading to an increase in circulating glucocorticoids (e.g., corticosterone) (Vissers et al., 2003, 2004), which can bind GRs in the amygdala to induce cellular changes. With regard to the present study, corticosterone and the HPA axis have been linked to mGluR5 and pain-related cellular and behavioral changes (Greenwood-Van Meerveld et al., 2001; Bradbury et al., 2003). As such, we wanted to know whether GR disruption in the amygdala would influence long-lasting mechanical hypersensitivity induced by persistent inflammation. As previously reported, lentiviral-mediated conditional CeAspecific GR knock-out ( $\mathrm{GR}^{\mathrm{CeAKO}}$ ) mice have GRs disrupted in $60-75 \%$ of neurons compared with control mice (Kolber et al., 2008). Here, mechanical thresholds were evaluated at baseline and $3 \mathrm{~h}$ after right hindpaw formalin injection in $\mathrm{GR}^{\mathrm{CeAKO}}$ and 
control mice. Formalin injection resulted in a significant reduction in mechanical sensitivity in both paws of GR ${ }^{\text {CeAKO }}$ and control mice. There were no significant differences between genotypes at any time point (Fig. 6D,E). These data suggest that GR expression in the CeA (and therefore endocrine feedback onto CeA neurons) is not necessary for formalin-induced mechanical hypersensitivity.

\section{Disruption of mGluR5 in the right} amygdala reduces inflammatory pain Both pharmacological inhibition of mGluR5 and global disruption of mGluR5 expression reduce inflammatory pain. Furthermore, mGluR5 expression is expressed at higher levels in the right amygdala relative to the left amygdala. These data are consistent with the hypothesis that mGluR5 activation in the right amygdala is critical to the behavioral response to formalininduced inflammation. To further test this hypothesis, a conditional knock-out approach was used to disrupt mGluR5 selectively in the right amygdala. Mice homozygous for the floxed-mGluR5 allele or WT littermates were injected into the right amygdala with recombinant lentivirus expressing Cre recombinase (LV-Cre). Floxed mGluR5 mice injected with LV-Cre (mGluR5 ${ }^{\mathrm{CeAKO}}$ ) exhibited a significant decrease in mGluR5 expression in the right amygdala compared with the right amygdala of LV-Cre-injected WT (control) mice (unpaired Student's $t$ test $p=0.01$ ) (Fig. 7A). Similar to WT mice above, control LVCre-injected mice exhibited significantly higher mGluR5 expression in the right amygdala relative to the left amygdala (paired Student's $t$ test $p=0.049$ ) (Fig. 7A). To address whether the observed decrease in mGluR5 expression (in mGluR5 ${ }^{\text {CeAKO }}$ mice) was specific or reflected an overall decrease in protein expression in amygdala tissue, we evaluated GR expression. No differences in amygdala GR expression were found between mGluR5 ${ }^{\text {CeAKO }}$ and control mice, and no significant lateralization of GR was found in either genotype (Fig. 7B).

To examine the behavioral effects of right amygdala mGluR5 disruption, we measured spontaneous formalin-induced behavior in mGluR5 ${ }^{\mathrm{CeAKO}}$ and control mice. In addition to changes to mechanical sensitivity, intraplantar formalin injection induces a stereotyped biphasic, spontaneous behavioral response in the first 60 min following injection (Tjolsen et al., 1992). Conventional global mGluR5 ${ }^{\mathrm{KO}}$ mice have a decreased second phase of this response (Montana et al., 2009). In contrast, we found no significant differences between mGluR $5^{\mathrm{CeAKO}}$ and control mice in either the first phase (control: $n=4,267.3 \pm 32.73 \mathrm{~s}$; mGluR5 ${ }^{\text {CeAKO }}: n=3,254.7 \pm 34.67 ; p=0.81$ ) or second phase (control: $n=4,709.8 \pm 39.89$ s; mGluR5 ${ }^{\text {CeAKO }}: n=3,685.3 \pm$ $44.46 ; p=0.48$ ) of spontaneous behavior testing (Fig. 7C).

Next, we examined mechanical sensitivity in mGluR5 ${ }^{\text {CeAKO }}$ mice and control mice under baseline conditions and following Student's $t$ test: ${ }^{+} p<0.05$.
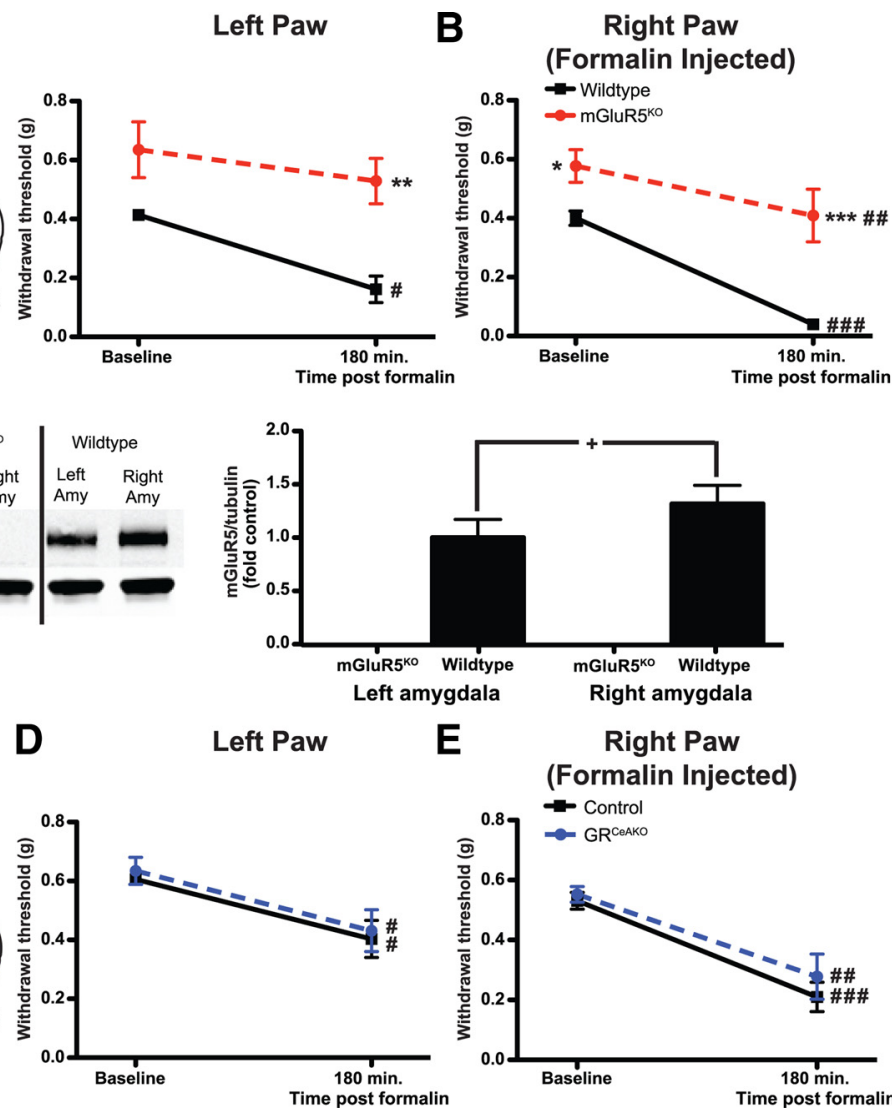

Time post formalin

Figure 6. Genetic disruption of $m G$ luR5 but not GR expression prevents normal formalin-induced mechanical hypersensitivity. $A, B$, In response to right paw formalin-injection, conventional mGluR5 ${ }^{\mathrm{K} 0}$ mice $(n=9)$ show no hypersensitivity in the left paw compared with baseline and reduced hypersensitivity in both paws compared with WT mice $(n=7)(\boldsymbol{A})$. mGluR5 ${ }^{\mathrm{K} 0}$ mice show increased basal withdrawal responses in the right paw compared with wild-type mice $(\boldsymbol{B})$. $\boldsymbol{C}$, Representative Western blots for

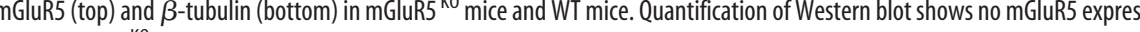
列 7). D, E, Deletion of $G R$ bilaterally ( $G R^{\text {CeAKO }}, n=9$ ) does not induce any behavioral changes under basal conditionsor a protein expression. Repeated measures ANOVA with Bonferroni post-test: ${ }^{* *} p<0.01,{ }^{* * *} p<0.001$, compared with control genotype at specified time point; ${ }^{\#} p<0.05,{ }^{\# \#} p<0.01,{ }^{\# \# \#} p<0.001$, compared with same genotype at baseline; paired

intraplantar formalin injection. In the von Frey test at baseline, mGluR5 ${ }^{\mathrm{CeAKO}}$ mice exhibited no significant differences in mechanical withdrawal thresholds compared with those of control mice (Fig. $7 D, E$ ). However, $3 \mathrm{~h}$ after formalin injection, mGluR5 CeAKO mice exhibited increased mechanical withdrawal thresholds in the von Frey Test compared with thresholds of control mice (Fig. $7 D, E$ ). When compared with baseline values, injection of formalin induced significant mechanical hypersensitivity in both hindpaws of control LV-Cre mice (Fig. 7D,E) but only induced significant hypersensitivity in the injected (right) hindpaws of mGluR5 ${ }^{\mathrm{CeAKO}}$ mice (Fig. $7 E$ ). Overall, these data suggest that mGluR5 expression in the right amygdala is necessary for normal formalin-induced hypersensitivity.

\section{Discussion}

The findings of this study provide a mechanistic framework for the emerging role of the amygdala in the modulation of persistent pain due to peripheral inflammation. We demonstrate that mGluR5 activation in the amygdala is sufficient to induce me- 


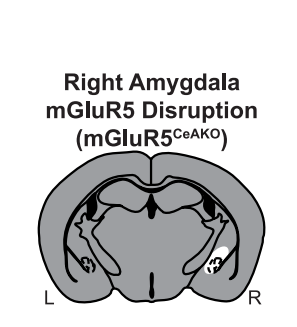

A
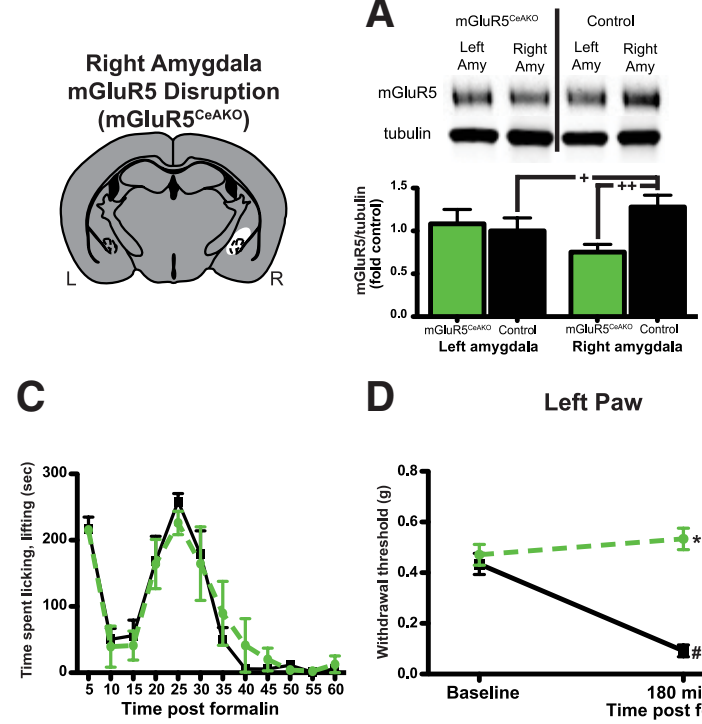

D

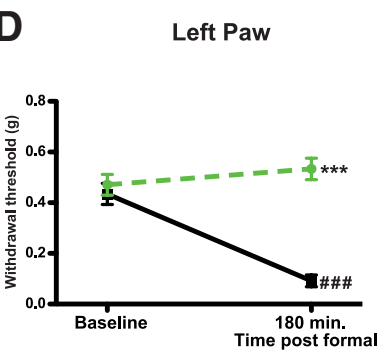

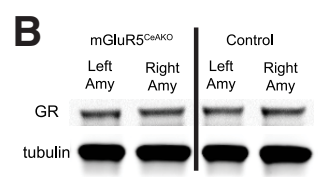

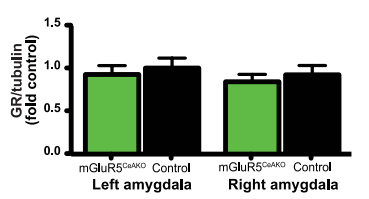

E Right Paw

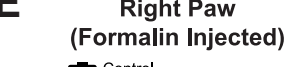

$\rightarrow$ Control

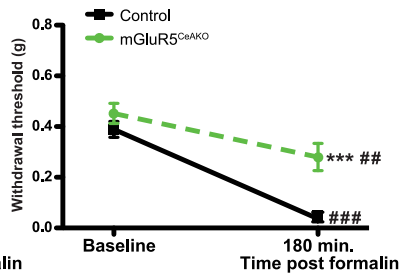

Figure 7. Conditional deletion of mGluR5 in the right amygdala prevents formalin-induced mechanical hypersensitivity. $\boldsymbol{A}$, Representative Western blot for mGluR5 (top) and $\beta$-tubulin (bottom) in mGluR5 ${ }^{\text {CeAKO }}$ and WT LV-Cre (control) mice. Graph of $\mathrm{mGluR5} / \beta$-tubulin shows reduced mGluR5 expression in the right amygdala of $\mathrm{mGluR5}{ }^{\text {CeAK0 }}$ mice $(n=6)$ [compared with the right amygdala of control mice $(n=6)]$. The graph also shows significantly higher mGluR5 expression in the right amygdala relative to the left amygdala in control mice. $\boldsymbol{B}$, Representative Western blot for glucocorticoid receptor (top) and $\beta$-tubulin (bottom) in mGluR5 ${ }^{\text {CeAKO }}$ mice and control mice. Graph shows no differences between mGluR5 ${ }^{\text {CAKO }}$ or control mice in GR expression in the right or left amygdala and no lateralization of GR expression in either genotype. C, mGluR5 ${ }^{\mathrm{CAKO}}$ mice show equivalent spontaneous behavior (lifting, licking, scratching of injected paw) following formalin injection compared with that of control mice. $\boldsymbol{D}, \boldsymbol{E}$, Disruption of mGluR5 in the right CeA leads to a complete block of hypersensitivity in the noninjected (left) paw (D) and reduced hypersensitivity in the injected (right) paw $(\boldsymbol{E})$ after formalin injection and reduced hypersensitivity in both paws compared with control mice. Gray area in brain illustration is representative of WT mGluR5 expression; white area in brain illustration is representative of $\mathrm{mGluR5}$ disruption in the rightCeA. Data are expressed as mean \pm SEM. Graphs of Western data are normalized to control left amygdala protein expression. Repeated-measures ANOVA with Bonferroni post-test: ${ }^{* *} p<0.001$ compared with control genotype at specified time point; ${ }^{\# \#} p<0.01,{ }^{\# \# \#} p<0.001$ compared with same genotype at baseline; paired Student's $t$ test: ${ }^{+} p<0.05$; unpaired Student's $t$ test: ${ }^{++} p=0.01$.

chanical hypersensitivity in the absence of injury and that mGluR5 activation is necessary for the development of mechanical hypersensitivity in response to inflammation. Furthermore, we provide evidence for hemispheric lateralization of amygdala function and mGluR5 expression. In addition, we find that mGluR5-related effects are linked to ERK1/2 activation in the amygdala. These results support the hypothesis that mGluR5 signaling via ERK phosphorylation in the right amygdala plays an important role in the neuromodulation of persistent pain.

Interestingly, we demonstrate that activation of group I mGluRs in the right amygdala is sufficient to induce bilateral mechanical hypersensitivity. This result is of particular relevance to pain conditions that exist in humans that do not have a known underlying etiology (e.g., fibromyalgia). As both mGluR1 and mGluR5 are expressed in the amygdala, we sought to clarify the necessity for mGluR5 in DHPG-induced hypersensitivity. Disruption of mGluR5 (pharmacologically or genetically) significantly reduces the effects of DHPG. These data suggest that mGluR5 activation alone in the right amygdala is sufficient to induce mechanical hypersensitivity but do not preclude a role for mGluR1 signaling in the amygdala during nociceptive processing.

The amygdala is involved in both ascending and descending components of nociceptive pathways (Bernard et al., 1989). Nociceptive input to the CeA via the spino-parabrachio-amygdaloid pathway or the BLA may provide a source of glutamatergic inputs to the CeLC (Neugebauer et al., 2004). As such, the amygdala is uniquely situated to modulate behavior during prolonged pain

conditions, such as those seen after intraplantar formalin injection. mGluR5 is necessary for the full expression of central sensitization and the exhibition of second phase nociceptive behaviors in the spontaneous formalin test (Bhave et al., 2001; Karim et al., 2001a; Adwanikar et al., 2004; Montana et al., 2009). Intraplantar formalin injection also induces persistent hypersensitivity to mechanical and thermal stimuli (Fu et al., 2001; Carrasquillo and Gereau, 2007). Interestingly, global mGluR5 disruption reduces but does not eliminate mechanical hypersensitivity in the formalin-injected paw. The observed reduction is only partial due to ongoing local inflammation at the site of formalin injection and resultant peripheral sensitization. However, a caveat of this finding is the demonstration that mGluR $5^{\mathrm{KO}}$ mice exhibit a reduced acute behavioral response to formalin injection in the paw (Montana et al., 2009) and hyporesponsiveness to mechanical stimulation under baseline conditions. The observation that mGluR5 antagonists do not alter baseline mechanical sensitivity in naive mice (Walker et al., 2001) suggests that our observed baseline differences in mGluR $5^{\mathrm{KO}}$ mice are likely a result of compensatory changes associated with global deletion of mGluR5.

To circumvent these issues, we developed a mouse with unilateral CeA-specific deletion of mGluR5 (mGluR5 ${ }^{\text {CeAKO}}$ ) by injecting the CeA of mice carrying floxed mGluR5 alleles (Xu et al., 2009) with a Cre recombinase-expressing lentivirus (Kolber et al., 2008). These mGluR5 ${ }^{\text {CeAKO }}$ mice had $\sim 40-50 \%$ reduction in mGluR5 expression in the right amygdala compared with control mice. This value may be an underestimate of disruption of mGluR5 in these mice due to the possible expression of mGluR5 in glial cells (Ferraguti et al., 2001). The observed reduction in mGluR5 protein expression does not reflect a nonspecific decrease in protein expression, as mGluR5 ${ }^{\text {CeAKO }}$ mice express equivalent amounts of GR protein compared with controls. mGluR5 ${ }^{\text {CeAKO }}$ mice show significant reduction in formalininduced mechanical hypersensitivity, but no changes in baseline sensitivity or spontaneous responses to formalin injection. These data are consistent with previous work showing that the amygdala is not involved in baseline nociception (Manning and Mayer, 1995b; Carrasquillo and Gereau, 2007) or acute formalin responses (Manning and Mayer, 1995a; Carrasquillo and Gereau, 2007).

To further test whether mGluR5 in the amygdala is necessary for prolonged mechanical hypersensitivity, we used a pharmacological approach in WT mice to block mGluR5 in the right amygdala after formalin paw injection. We found that formalin-induced mechanical hypersensitivity was reduced after right CeA MPEP infusion in a manner similar to that seen with global mGluR5 ${ }^{\mathrm{KO}}$ mice, consistent with the finding that group I mGluR antagonists in the amygdala can inhibit pain-like behaviors (Han and Neugebauer, 2005). In addition, MPEP reversed hypersensitivity that had already developed be- 
fore intra-amygdala drug infusions, suggesting that mGluR5 activation in the amygdala may be involved in the maintenance of persistent pain-like behavior.

Our data indicate that some aspects of mGluR 5 modulation of pain-like behavior are lateralized to the right amygdala. We find a higher level of mGluR5 expression in the right amygdala compared with expression in the left amygdala under normal conditions. These findings are not without precedent, as hemispheric lateralization of amygdala function has been reported in both humans (Coghill et al., 2001; Cahill et al., 2004; Lu et al., 2004; Alkire et al., 2008) and rodents (Lalumiere and McGaugh, 2005; Ji and Neugebauer, 2009). Previously, we established that during formalin-induced inflammation, there is a selective activation of ERK1/2 in the right CeLC that can be blocked with the MEK1/2 inhibitor U0126 (Carrasquillo and Gereau, 2008). In addition, recent data show hemispheric lateralization of amygdala sensitization in arthritis (Ji and Neugebauer, 2009). Interestingly, in that study, neurons of the right CeLC showed whole-body receptive fields, while left CeLC neurons showed more restricted contralateral receptive fields. Our observation of baseline differences in mGluR5 protein reflects either more mGluR5 protein per cell in the right amygdala or expression of mGluR5 in an additional population of cells in the right amygdala relative to the left. Although future studies will be needed to clarify this issue, the data showing larger receptive fields of right amygdala neurons (Ji and Neugebauer, 2009), our data showing that DHPG infusion in the right amygdala induced bilateral tactile hypersensitivity whereas DHPG infusion in the left amygdala induced mechanical hypersensitivity in the right (contralateral) paw only, and our data showing that MPEP could reverse formalin-induced mechanical hypersensitivity when infused into the right but not left amygdala suggest that there may be a unique population of cells in the right amygdala that have bilateral connections within the CNS.

Three lines of evidence suggest that amygdalar mGluR5 is functionally coupled to ERK and that this signaling pathway is involved in endogenous pain modulation. First, we show that activation of mGluR5 in the right amygdala induces activation of ERK1/2. Second, we demonstrate that the behavioral effects of DHPG can be reduced following coinfusion with the MEK inhibitor U0126. Finally, we show that mGluR5 inhibition in the right amygdala blocks formalin-induced ERK1/2 activation in the right amygdala. In the CeA, ERK $1 / 2$ is both necessary and sufficient for formalin-induced mechanical hypersensitivity (Carrasquillo and Gereau, 2007, 2008). In the spinal cord dorsal horn, mGluR5-induced ERK activation modulates both spontaneous behavioral responses to formalin and neuronal excitability via increasing ion channel phosphorylation (Karim et al., 2001a; $\mathrm{Hu}$ and Gereau, 2003; Hu et al., 2007). Additional studies will be necessary to determine whether similar mechanisms are responsible for DHPG-induced modulation of behavior at the level of the amygdala. Interestingly, coinfusion of DHPG with the MEK inhibitor U0126 caused only a partial reversal of DHPG-induced mechanical hypersensitivity. These data suggest signaling pathways unrelated to ERK may be involved in mGluR5-related behavioral changes.

During stressful events, including formalin injection (Vissers et al., 2003, 2004), the HPA axis is activated causing the release of corticosterone, which binds to GR. Corticosterone-induced activation of amygdalar GR can increase colorectal distension-induced, pain-related responses in rats (Greenwood-Van Meerveld et al., 2001). Furthermore, systemic MPEP induces HPA axis activation, suggesting the possible presence of a functional coupling of mGluR5 and the endocrine stress response (Bradbury et al., 2003). To test the hypothesis that amygdalar GR is playing an underlying role in formalin-induced mechanical hypersensitivity, we evaluated this behavior after bilateral conditional knock-out of GR in the CeA. We found no differences in formalin-induced mechanical hypersensitivity in these $\mathrm{GR}^{\mathrm{CeAKO}}$ mice, although it is possible that the remaining population of GR-positive neurons was able to maintain normal feedback during inflammatory pain. However, this is unlikely because we described previously a reduction in conditioned fear in $\mathrm{GR}^{\mathrm{CeAKO}}$ mice with only $65 \%$ CeA GR disruption (Kolber et al., 2008).

Overall, we show that CeA mGluR5 activation is both necessary for the development of inflammatory pain-like behavior and sufficient to induce mechanical hypersensitivity in the absence of injury. Furthermore, we demonstrate that the behavioral effects of mGluR5 activation are mediated via ERK activation in the CeA. In addition, we find hemispheric differences in mGluR5 expression and mGluR5 activation-induced behavior. Our results have important implications for understanding chronic pain in human patients. Specifically, we identify mGluR5 as an important cellular component of amygdala pain modulation, which may provide a molecular connection to the known efficacy of cognitive and behavioral approaches to pain treatment in human patients; our results demonstrate a specific anatomical location that may underlie some of the many preclinical studies showing the potential efficacy of mGluR5 antagonists in the treatment of pain.

\section{References}

Adwanikar H, Karim F, Gereau RW (2004) Inflammation persistently enhances nocifensive behaviors mediated by spinal group I mGluRs through sustained ERK activation. Pain 111:125-135.

Alkire MT, Gruver R, Miller J, McReynolds JR, Hahn EL, Cahill L (2008) Neuroimaging analysis of an anesthetic gas that blocks human emotional memory. Proc Natl Acad Sci U S A 105:1722-1727.

Ansah OB, Goncalves L, Almeida A, Pertovaara A (2009) Enhanced pronociception by amygdaloid group I metabotropic glutamate receptors in nerve-injured animals. Exp Neurol 216:66-74.

Bernard JF, Peschanski M, Besson JM (1989) A possible spino (trigemino)ponto-amygdaloid pathway for pain. Neurosci Lett 100:83-88.

Bhave G, Karim F, Carlton SM, Gereau RW (2001) Peripheral group I metabotropic glutamate receptors modulate nociception in mice. Nat Neurosci 4:417-423.

Bradbury MJ, Giracello DR, Chapman DF, Holtz G, Schaffhauser H, Rao SP, Varney MA, Anderson JJ (2003) Metabotropic glutamate receptor 5 antagonist-induced stimulation of hypothalamic-pituitary-adrenal axis activity: interaction with serotonergic systems. Neuropharmacology 44:562-572.

Cahill L, Uncapher M, Kilpatrick L, Alkire MT, Turner J (2004) Sex-related hemispheric lateralization of amygdala function in emotionally influenced memory: an FMRI investigation. Learn Mem 11:261-266.

Carrasquillo Y, Gereau RW (2007) Activation of the extracellular signalregulated kinase in the amygdala modulates pain perception. J Neurosci 27:1543-1551.

Carrasquillo Y, Gereau RW (2008) Hemispheric lateralization of a molecular signal for pain modulation in the amygdala. Mol Pain 4:24.

Coghill RC, Gilron I, Iadarola MJ (2001) Hemispheric lateralization of somatosensory processing. J Neurophysiol 85:2602-2612.

Ferraguti F, Corti C, Valerio E, Mion S, Xuereb J (2001) Activated astrocytes in areas of kainate-induced neuronal injury upregulate the expression of the metabotropic glutamate receptors 2/3 and 5. Exp Brain Res 137:1-11.

Fu KY, Light AR, Maixner W (2001) Long-lasting inflammation and longterm hyperalgesia after subcutaneous formalin injection into the rat hindpaw. J Pain 2:2-11.

Greenwood-Van Meerveld B, Gibson M, Gunter W, Shepard J, Foreman R, Myers D (2001) Stereotaxic delivery of corticosterone to the amygdala modulates colonic sensitivity in rats. Brain Res 893:135-142.

Han JS, Neugebauer V (2005) mGluR1 and mGluR5 antagonists in the amygdala inhibit different components of audible and ultrasonic vocalizations in a model of arthritic pain. Pain 113:211-222. 
Hu HJ, Gereau RW (2003) ERK integrates PKA and PKC signaling in superficial dorsal horn neurons. II. Modulation of neuronal excitability. J Neurophysiol 90:1680-1688.

Hu HJ, Glauner KS, Gereau RW (2003) ERK integrates PKA and PKC signaling in superficial dorsal horn neurons. I. Modulation of A-type K+ currents. J Neurophysiol 90:1671-1679.

Hu HJ, Alter BJ, Carrasquillo Y, Qiu CS, Gereau RW (2007) Metabotropic glutamate receptor 5 modulates nociceptive plasticity via extracellular signal-regulated kinase-Kv4.2 signaling in spinal cord dorsal horn neurons. J Neurosci 27:13181-13191.

Ikeda R, Takahashi Y, Inoue K, Kato F (2007) NMDA receptor-independent synaptic plasticity in the central amygdala in the rat model of neuropathic pain. Pain 127:161-172.

Ji G, Neugebauer V (2009) Hemispheric lateralization of pain processing by amygdala neurons. J Neurophysiol 102:2253-2264.

Jia Z, Lu Y, Henderson J, Taverna F, Romano C, Abramow-Newerly W, Wojtowicz JM, Roder J (1998) Selective abolition of the NMDA component of long-term potentiation in mice lacking mGluR5. Learn Mem 5:331-343.

Karim F, Wang CC, Gereau RW (2001a) Metabotropic glutamate receptor subtypes 1 and 5 are activators of extracellular signal-regulated kinase signaling required for inflammatory pain in mice. J Neurosci 21:37713779.

Karim F, Bhave G, Gereau RW (2001b) Metabotropic glutamate receptors on peripheral sensory neuron terminals as targets for the development of novel analgesics. Mol Psychiatry 6:615-617.

Kolber BJ, Roberts MS, Howell MP, Wozniak DF, Sands MS, Muglia LJ (2008) Central amygdala glucocorticoid receptor action promotes fearassociated CRH activation and conditioning. Proc Natl Acad Sci U S A 105:12004-12009.

Lalumiere RT, McGaugh JL (2005) Memory enhancement induced by posttraining intrabasolateral amygdala infusions of beta-adrenergic or muscarinic agonists requires activation of dopamine receptors: involvement of right, but not left, basolateral amygdala. Learn Mem 12:527-532.

Li W, Neugebauer V (2004) Differential roles of mGluR1 and mGluR5 in brief and prolonged nociceptive processing in central amygdala neurons. J Neurophysiol 91:13-24.

Lu CL, Wu YT, Yeh TC, Chen LF, Chang FY, Lee SD, Ho LT, Hsieh JC (2004) Neuronal correlates of gastric pain induced by fundus distension: a 3TfMRI study. Neurogastroenterol Motil 16:575-587.

Manning BH, Mayer DJ (1995a) The central nucleus of the amygdala contributes to the production of morphine antinociception in the formalin test. Pain 63:141-152.

Manning BH, Mayer DJ (1995b) The central nucleus of the amygdala contributes to the production of morphine antinociception in the rat tail-flick test. J Neurosci 15:8199-8213.
Montana MC, Cavallone LF, Stubbert KK, Stefanescu AD, Kharasch ED, Gereau RW (2009) The metabotropic glutamate receptor subtype 5 antagonist fenobam is analgesic and has improved in vivo selectivity compared with the prototypical antagonist 2-methyl-6-(phenylethynyl)pyridine. J Pharmacol Exp Ther 330:834-843.

Neugebauer V, Li W, Bird GC, Bhave G, Gereau RW (2003) Synaptic plasticity in the amygdala in a model of arthritic pain: differential roles of metabotropic glutamate receptors 1 and 5. J Neurosci 23:52-63.

Neugebauer V, Li W, Bird GC, Han JS (2004) The amygdala and persistent pain. Neuroscientist 10:221-234.

Romano C, Sesma MA, McDonald CT, O’Malley K, Van den Pol AN, Olney JW (1995) Distribution of metabotropic glutamate receptor mGluR5 immunoreactivity in rat brain. J Comp Neurol 355:455-469.

Ryo Y, Miyawaki A, Furuichi T, Mikoshiba K (1993) Expression of the metabotropic glutamate receptor mGluR1 alpha and the ionotropic glutamate receptor GluR1 in the brain during the postnatal development of normal mouse and in the cerebellum from mutant mice. J Neurosci Res 36:19-32.

Schneider F, Habel U, Holthusen H, Kessler C, Posse S, Muller-Gartner HW, Arndt JO (2001) Subjective ratings of pain correlate with subcorticallimbic blood flow: an fMRI study. Neuropsychobiology 43:175-185.

Tjolsen A, Berge OG, Hunskaar S, Rosland JH, Hole K (1992) The formalin test: an evaluation of the method. Pain 51:5-17.

Varney MA, Gereau RW (2002) Metabotropic glutamate receptor involvement in models of acute and persistent pain: prospects for the development of novel analgesics. Curr Drug Targets CNS Neurol Disord 1:283-296.

Vissers K, Adriaensen H, De Coster R, De Deyne C, Meert TF (2003) A chronic-constriction injury of the sciatic nerve reduces bilaterally the responsiveness to formalin in rats: a behavioral and hormonal evaluation. Anesth Analg 97:520-525.

Vissers KC, De Jongh RF, Crul BJ, Vinken P, Meert TF (2004) Adrenalectomy affects pain behavior of rats after formalin injection. Life Sci 74:1243-1251.

Walker K, Bowes M, Panesar M, Davis A, Gentry C, Kesingland A, Gasparini F, Spooren W, Stoehr N, Pagano A, Flor PJ, Vranesic I, Lingenhoehl K, Johnson EC, Varney M, Urban L, Kuhn R (2001) Metabotropic glutamate receptor subtype 5 (mGlu5) and nociceptive function. I. Selective blockade of mGlu5 receptors in models of acute, persistent and chronic pain. Neuropharmacology 40:1-9.

Xu J, Zhu Y, Contractor A, Heinemann SF (2009) mGluR5 has a critical role in inhibitory learning. J Neurosci 29:3676-3684.

Yang D, Gereau RW (2003) Peripheral group II metabotropic glutamate receptors mediate endogenous anti-allodynia in inflammation. Pain 106: 411-417. 